\title{
PENGARUH FORMULASI DAN LAMA PENYIMPANAN PADA VIABILITAS, BIOAKTIVITAS DAN PERSISTENSI CENDAWAN METARHIZIUM ANISOPLIAE TERHADAP CROCIDOLOMIA PAVONANA FABRICIUS
}

\author{
Nuraida \& Aisyah Lubis \\ Program Studi Agroteknologi Fakultas Pertanian Universitas Al-Azhar Medan \\ Jl. Pintu Air IV No. 214 Kwala Bekala Padang Bulan Medan \\ E-mail : nuraida617@yahoo.co.id
}

\begin{abstract}
Effects of formulations and storage length on the viability, bioactivity and persistence of Metarhizium anisopliae against Crocidolomia pavonana Fabricius. Crocidolomia pavonana Fabricius (Lepidoptera: Pyralidae) is important pest on vegetables form Brassicaceae family, that required to be control. Metarhizium anisopliae entomopathogenic fungus is one potensial of the biological agent that can be used to control $C$. pavonana. This study aimed to investigated the effect of storage duration on viability, bioactivity and persistence of $M$. anisopliae after formulated to control $C$. pavonana. Laboratory experiment was arranged in completely randomized design with the treatment was storage duration that included 2,4,6,8 and 10 weeks that replicated three trials. The variabels to be measured were viability and bioactivity at concentrations $10^{6}, 10^{7}$, and $10^{8}$. Field experiment used T Student test with treatment was duration of M. anisopliae formulation survive and its persistence on $C$. pavonana. Laboratory experiment results showed that the best storage duration of formulation on Metarhizium viability was pellet frmulation at $4^{\text {th }}$ week 4 after storage. While the best bioactivity was pellet formulation with concentration $10^{7}$ at 10 weeks after storage. Field experiment results showed that M. anisopliae formulation could be survived and its persistence to control pests $C$. pavonana until $4^{\text {th }}$ day after application, either pellet or powder formulation.
\end{abstract}

Key words: entomopathogenic fungi, formulation, M. anisopliae, viability and persistence

\section{ABSTRAK}

Pengaruh formulasi dan lama penyimpanan pada viabilitas, bioaktivitas dan persistensi cendawan Metarhizium anisopliae terhadap Crocidolomia pavonana Fabricius. Crocidolomia pavonana Fabricius (Lepidoptera: Pyralidae) merupakan hama penting pada tanaman sayuran dari famili Brassicaceae yang memerlukan pengendalian. Cendawan entomopatogen Metarhizium anisopliae merupakan salah satu agensia hayati yang potensial dimanfaatkan untuk pengendalian hama $C$. pavonana. Penelitian ini bertujuan untuk mengetahui pengaruh lamanya penyimpanan pada viabilitas, bioaktivitas dan persistensi cendawan M. anisopliae yang di formulasi untuk mengendalikan hama C. pavonana. Percobaan laboratorium menggunakan Rancangan Acak Lengkap (RAL), meliputi lamanya penyimpanan cendawan (2, 4, 6, 8 dan 10 minggu) terhadap viabilitas dan bioaktivitasnya pada konsentrasi $10^{6}, 10^{7}$, dan $10^{8}$. Percobaan lapangan menggunakan rancangan Uji Student T, meliputi perlakuan lamanya formula $M$. anisopliae bertahan dilapangan serta persistensinya terhadap $C$. pavonana. Hasil percobaan laboratorium menunjukkan bahwa lamanya penyimpanan formulasi terhadap viabilitas cendawan metarhizium yang paling baik adalah pada formulasi pelet yaitu pada minggu ke 4 setelah penyimpanan. Sedangkan bioaktivitas paling baik terdapat pada minggu ke 10 setelah penyimpanan yaitu pada formulasi pelet dengan konsentrasi $10^{7}$. Hasil percobaan lapang menunjukkan bahwa formula $M$. anisopliae dapat bertahan di lapangan serta persistensinya untuk mengendalikan hama $C$. pavonana hanya sampai hari ke 4 setelah aplikasi, baik formulasi pelet maupun formulasi tepung.

Kata kunci : formulasi, jamur entomopatogen, M. anisopliae, viabilitas dan persistensi

\section{PENDAHULUAN}

Crocidolomia pavonana Fabricius (Lepidoptera: Pyralidae) merupakan salah satu hama penting pada tanaman sayuran dari familia Brassicaceae (kubis, brokoli, kubis bunga, sawi dan lobak) (Kalshoven, 1981). Larva $C$. pavonana lebih menyukai daun muda, kemudian menuju titik tumbuh tanaman kubis. Bila serangan berat dapat menyebabkan tanaman kubis tidak bisa membentuk krop (Kalshoven, 1981). Kerusakan 
yang disebabkan oleh hama ini dapat mencapai 100\% bila tidak dilakukan pengendalian secara tepat.

Sampai saat ini pengendalian hama $C$. pavonana para petani masih mengandalkan insektisida sintetik, karena mereka menganggap insektisida kimia merupakan jaminan untuk keberhasilan usaha taninya, selain masih belum ditemukannya cara pengendalian lain yang lebih efektif. Aplikasi insektisida kimia dilakukan secara berkala seminggu sekali bahkan 2 atau 3 hari sekali dan bahan kimia yang disemprotkan merupakan campuran dari berbagai jenis insektisida. Hal ini sangat disayangkan mengingat Indonesia sedang menuju era pembangunan pertanian yang berwawasan lingkungan, sehingga penggunaan insektisida sintetik harus digunakan seminimal mungkin. Pengendalian hayati dengan memanfaatkan mikroba patogen seperti cendawan entomopatogen (Metarhizium), berpotensi sebagai pengendalian alternatif menggantikan insektisida sintetik. Selain itu memberdayakan musuh alami dan potensi biologi lainnya merupakan komponen utama, karena musuh alami mempunyai peranan yang penting dalam penekanan populasi hama dan menjaga keseimbangan ekosistem. Oleh karena itu musuh alami yang sudah ada pada ekosistem setempat perlu dijaga kelestariannya dan upaya untuk meningkatkan peranannya dalam pengendalian hama juga perlu dilakukan.

Penelitian tentang aplikasi cendawan $M$. anisopliae untuk pengendalian hama telah banyak dilakukan mulai dari eksplorasi dan seleksi strain-strain isolat (Luz et al., 1998; Myles, 2002; Nuraida \& Hasyim, 2009; Hasyim et al., 2009). Cendawan Metarhizium sp. dilaporkan dapat diproduksi secara massal pada media seperti SDB (Sobouraud Dextrose Broth) atau SDA (Sabouroud Dextrose Agar) (Prayogo et al., 2005) dan diformulasikan sebagai bioinsektisida baik dalam bentuk padat maupun cair (Alves et al., 2002; Geden \& Steinkraus, 2003). Dalam rangka pemanfaatan cendawan entomopatogen sebagai agensia pengendali hayati hama $C$. pavonana, pemilihan jenis dan isolat cendawan entomopatogen yang virulen terhadap hama $C$. pavonana merupakan hal yang penting. Di samping faktor virulensi, kemampuan patogen untuk bisa hidup dan bertahan di lingkungan serta menyebar di dalam populasi hama merupakan salah satu faktor penting dalam keberhasilan pengendalian hayati. Propagul cendawan yang memiliki persistensi dan transmisi yang baik akan mempunyai peluang yang lebih besar untuk bisa kontak dengan serangga dan menimbulkan penyakit (Inglis et al., 2001). Keberhasilan cendawan Metarhizium di lapangan belum konsisten, hal ini disebabkan oleh faktor antara lain viabilitas, virulensi, kondisi lingkungan dan formulasi. Untuk menjaga viabilitas dan virulensinya maka dilakukan pengawetan dengan membuat formulasi yaitu pelet dan tepung. Sebagaimana yang dinyatakan oleh Bustamante dalam Junianto \& Sulistyowati (2000), bahwa untuk menjaga viabilitas ataupun virulensinya, spora cendawan entomopatogen dapat diawetkan dengan cara pengeringan karena pada kadar air rendah aktivitas metabolismenya kecil. Spora Metarhizium sama halnya dengan spora Beauveria bassiana bila dikeringanginkan masih dapat bertahan hidup sampai 2 tahun bila disimpan pada suhu $5{ }^{\circ} \mathrm{C}$, sedangkan spora yang tidak diawetkan hanya berumur beberapa minggu. Viabilitas (daya kecambah), pertumbuhan, virulensi dan persistensi Metarhizium sp. sangat dipengaruhi oleh faktor ligkungan fisik. Suhu optimum untuk pertumbuhan berkisar $22-27^{\circ} \mathrm{C}$ (Roddom \& Rath, 2000). Kelembaban yang dibutuhkan cendawan Metarhizium sp. membentuk kecambah di atas $90 \%$ dan pada kelembaban yang semakin tinggi cendawan semakin virulen. Virulensi cendawan ini akan semakin menurun dengan semakin menurunnya kelembaban udara (Milner et el., 1997). Pada kelembaban udara yang lebih rendah dari $86 \%$ virulensi cendawan akan terus menurun (Bidochka et al., 2000). Viabilitas cendawan sangat mempengaruhi pertumbuhan berikutnya. Semakin banyak konidia berkecambah, semakin cepat pertumbuhan cendawan tersebut dan semakin cepat menimbulkan kematian pada serangga uji tersebut (Prayogo et al., 2005).

Faktor penting dalam keberhasilan pengendalian hayati adalah kemampuan dari patogen tersebut untuk bisa hidup dan bertahan di lingkungan. Propagul cendawan yang memiliki persistensi yang baik akan mempunyai peluang yang lebih besar untuk bisa kontak dengan serangga dan menimbulkan penyakit (Inglis et al., 2001). M. anisopliae selain mudah ditularkan pada berbagai jenis serangga, juga mudah diperbanyak pada substrat yang sederhana dan konidia memiliki persistensi yang lama di dalam tanah (Goettel, 1992).

\section{METODE PENELITIAN}

Tempat dan Waktu. Pelaksanaan penelitian dibagi menjadi dua percobaan. Percobaan I dilaksanakan di Laboratorium Hama dan Penyakit Fakultas Pertanian Universitas Al-Azhar Medan, mulai bulan Maret sampai Juli 2014. Percobaan II dilaksanakan di Kebun masyarakat Kabupaten Tanah Karo, mulai bulan Juni sampai September 2014.

Formulasi isolat $M$. anisopliae. Isolat cendawan entomopatogen M. anisopliae diformulasi dalam bentuk 
pelet alginat (Gambar 1A) dengan menggunakan metode yang dikemukakan oleh Bextine \& Thorvilson (2002). Larutan sodium alginat diperoleh dengan cara melarutkan 2,5 g sodium alginat kedalam $10 \mathrm{ml}$ etanol 95\%. Selanjutnya konidia cendawan (pada media jagung) sebanyak $37 \mathrm{~g}$ dimasukkan kedalam $100 \mathrm{ml}$ larutan sodium alginat. Suspensi dicampur sampai homogen di dalam blender. Selama pencampuran, suspensi ditetesi dengan larutan kalsium glukonat 0,25 $\mathrm{M}$ dengan menggunakan pipet steril sebnyak $10 \mathrm{ml}$. Pelet yang dihasilkan disaring dan dikeringkan. Formula yang dihasilkan diuji lama penyimpanannya dan viabilitasnya (pada 2, 4, 6, 8, dan 10 minggu setelah dibuat formulasi).

Selain dalam bentuk pelet alginat, cendawan $M$. anisopliae juga diformulasi dalam bentuk tepung (WP) (Gambar 1B). Konidia M. anisopliae dicampur dengan bahan pembawa berupa talk dengan perbandingan 1:10, dan bahan aditif sampai homogen. Formula yang dihasilkan diuji lama penyimpanan dan viabilitasnya pada 2, 4, 6, 8, dan 10 minggu setelah dibuat formulasi.

Viabilitas cendawan dihitung dengan menggunakan rumus Gabriel \& Riyatno (1989) sebagai berikut:

$$
\mathrm{V}=\frac{\mathrm{g}}{\mathrm{g}+\mathrm{u}} \times 100 \%
$$

dengan:

$\mathrm{V}=$ Perkecambahan spora (Viabilitas)

$\mathrm{g}=$ Jumlah spora yang berkecambah

$\mathrm{u}=$ jumlah spora yang tidak berkecambah

Kerapatan konidia dihitung dengan menggunakan rumus Gabriel \& Riyatno (1989) sebagai berikut:

$$
\mathrm{C}=\frac{\mathrm{t}}{\mathrm{n} \cdot \mathrm{x}} \times 10^{6}
$$

dengan:

$\mathrm{C}=$ kerapatan spora per ml larutan

$\mathrm{t}=$ jumlah total spora dalam kotak sampel yang diamati

$\mathrm{n}=$ jumlah kotak sampel (5 kotak besar $\mathrm{x} 16$ kotak kecil) $\mathrm{x}=0,25$ faktor koreksi penggunaan kotak sampel skala kecil pada haemocytometer

Selanjutnya isolat $M$. anisopliae yang telah diformulasi diuji bioaktivitasnya terhadap larva $C$. pavonana. Percobaan ini menggunakan Rancangan Acak Lengkap (RAL). Pengujian dilakukan dengan cara penyemprotan formulasi pada larva instar 2 C. pavonana dengan beberapa konsentrasi $\left(10^{6}, 10^{7}\right.$, $10^{8}$ dan Kontrol). Larva C. pavonana yang telah disemprot dimasukkan ke dalam kotak plastik dan diberi makan dengan daun kubis yang sudah dicuci bersih dengan akuades. Mortalitas larva diamati setiap hari sampai 7 hari setelah aplikasi.

Pemeliharaan Serangga Uji. Larva $C$. pavonana dikumpulkan dari pertanaman kubis di lapangan. Larvalarva ini dipelihara dalam kotak plastik dan diberi makanan berupa daun kubis yang masih segar. Makanan larva diganti setelah habis atau sudah tidak segar lagi.

Pada waktu larva akan berpupa, di dasar kotak diberi serbuk gergaji. Semua imago yang keluar dari pupa dipelihara dalam kurungan serangga yang telah diberi daun kubis segar sebagai tempat peletakan telur. Imago diberi pakan madu yang telah diencerkan dengan konsentrasi $10 \%$. Kelompok telur yang diletakkan dipindahkan ke kotak lain dan larva instar 1 yang muncul dipelihara sampai menjadi instar 2 yang digunakan untuk pengujian.

Percobaan tahap II menggunakan Metode Student $\mathrm{T}$, dengan faktor yang diuji adalah lamanya formulasi cendawan $M$. anisopliae bertahan di lapangan. Pengujian dilakukan dengan cara, tanaman kubis yang telah berumur 2 bulan setelah tanam disemprot satu kali dengan suspensi konidia $M$. anisopliae yang telah diformulasi sebayak $100 \mathrm{ml} /$ tanaman. Konsentrasi konidia yang digunakan adalah $10^{8} \mathrm{konidia} / \mathrm{ml}$. Masing-masing perlakuan diberi bahan perekat $0,05 \%$ Tween 80 .
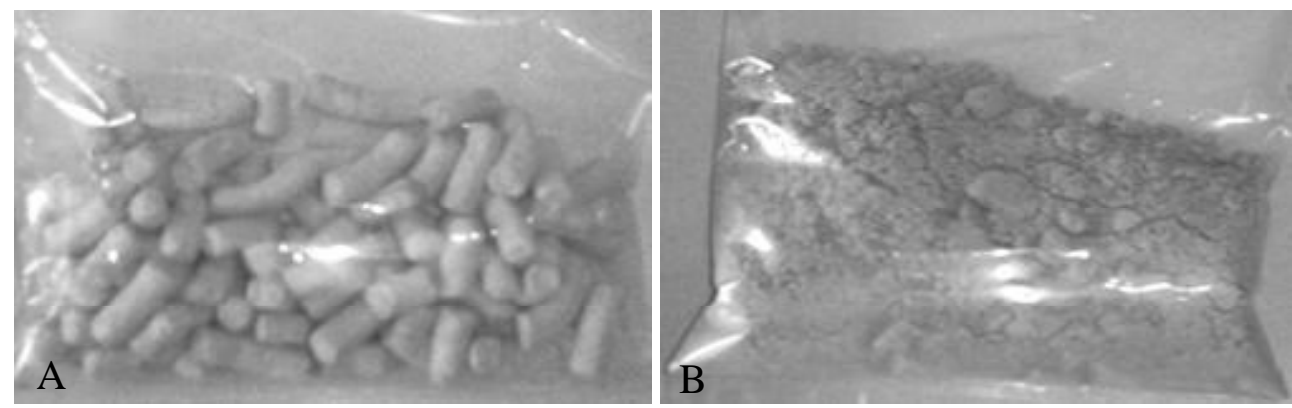

Gambar 1. Formulasi Jamur M. anisopliae, (A) Pelet; (B) Tepung 
Penyemprotan konidia dilakukan pada permukaan atas dan bawah daun kubis dengan menggunakan handsprayer. Tanaman diberi naungan dengan atap plastik agar terhindar dari air hujan. Atap dapat dibuka kalau tidak ada hujan agar tanaman dapat terkena sinar matahari langsung. Segera setelah penyemprotan, daun kubis masing-masing perlakuan diambil dan diberikan sebagai makanan larva $C$. pavonana instar 2 sebanyak 20 ekor di laboratorium. Makanan larva diganti setiap hari dari tanaman yang sama sampai dengan hari ke-7. Mortalitas larva diamati setiap hari sampai dengan hari ke-7.

\section{HASIL DAN PEMBAHASAN}

\section{Kerapatan Konidia dan Viabilitas cendawan $M$.} anisopliae. Berdasarkan hasil pengamatan yang dilakukan terhadap lamanya penyimpanan dan viabilitasnya mulai dari 2 sampai 10 minggu setelah penyimpanan, setelah data diolah secara statistik menunjukkan tidak berbeda nyata (Tabel 1).

Dari Tabel 1 terlihat bahwa kepadatan konidia setelah 2 minggu penyimpanan antara bentuk pelet dan tepung berbeda tidak nyata, begitu juga dengan minggu ke-4 sampai minggu ke-10 setelah penyimpanan. Tetapi kerapatan konidia yang tertinggi terdapat pada minggu ke-4 atau 1 bulan setelah penyimpanan yaitu pada formulasi pelet $\left(8,75 \times 10^{9}\right.$ konidia/ml $)$ dan tepung $\left(8,91 \times 10^{9}\right.$ konidia/ml). Hal ini sesuai dengan hasil penelitian Thalib et al. (2012) menyatakan bahwa, kerapatan konidia tertinggi terdapat pada umur simpan 1 bulan maupun umur simpan 4 bulan. Sedangkan kerapatan konidia terendah terdapat pada minggu ke 10 setelah penyimpanan, yaitu formulasi pelet $\left(6,0 \times 10^{9}\right)$ dan formulasi tepung $\left(4,75 \times 10^{9}\right)$, tetapi juga tidak berbeda nyata dengan lama penyimpanan lainnya.

Tinggi rendahnya kerapatan konidia tergantung pada bahan pembawa. Sebagaimana yang dinyatakan oleh Effendy (2010) bahwa bahan pembawa berpengaruh nyata terhadap kerapatan konidia cendawan Metarhizium sp.

Viabilitas cendawan Metarhizium setelah beberapa minngu penyimpanan, setelah data dianalisis secara statistik berbeda tidak nyata antar perlakuan dan antar waktu penyimpanan (Tabel 1 dan Gambar 2).

Dari Tabel 1 viabilitas (persentase perkecambahan) cendawan setelah penyimpanan 2,4 , 6, 8 dan 10 minggu berbeda tidak nyata antar setiap waktu penyimpanan. Akan tetapi untuk viabilitas tertinggi terdapat pada waktu penyimpanan 2 minGgu setelah di buat formulasi, baik formulasi pelet maupun tepung, dengan jumlah masing-masing $85 \%$ dan $90 \%$.

Tabel 1. Kerapatan konidia dan viabilitas cendawan entomopatogen $M$. anisopliae setelah beberapa minggu penyimpanan dalam bentuk pelet dan tepung

\begin{tabular}{|c|c|c|c|c|c|c|c|c|c|c|}
\hline \multirow{3}{*}{ Formulasi } & \multicolumn{10}{|c|}{$\begin{array}{c}\text { Kerapatan konidia dan viabilitas cendawan } M \text {. anisopliae } \\
\text { setelah penyimpanan (Minggu ke....) }\end{array}$} \\
\hline & \multicolumn{2}{|c|}{2} & \multicolumn{2}{|c|}{4} & \multicolumn{2}{|c|}{6} & \multicolumn{2}{|c|}{8} & \multicolumn{2}{|c|}{10} \\
\hline & KK & $\mathrm{Vb}$ & KK & $\mathrm{Vb}$ & KK & $\mathrm{Vb}$ & KK & $\mathrm{Vb}$ & KK & $\mathrm{Vb}$ \\
\hline Pelet & $3,26 \times 10^{9}$ & 85,00 & $8,75 \times 10^{9}$ & 85,00 & $6,02 \times 10^{9}$ & 84,50 & $4,93 \times 10^{9}$ & 82,50 & $6,00 \times 10^{9}$ & 78,75 \\
\hline Tepung & $1,14 \times 10^{9}$ & 90,00 & $8,91 \times 10^{9}$ & 87,50 & $6,33 \times 10^{9}$ & 83,70 & $4,92 \times 10^{9}$ & 81,25 & $4,75 \times 10^{9}$ & 79,50 \\
\hline
\end{tabular}

$\mathrm{KK}=$ Kerapatan konidia (konidia/ml), $\mathrm{Vb}=$ Viabilitas (\%)
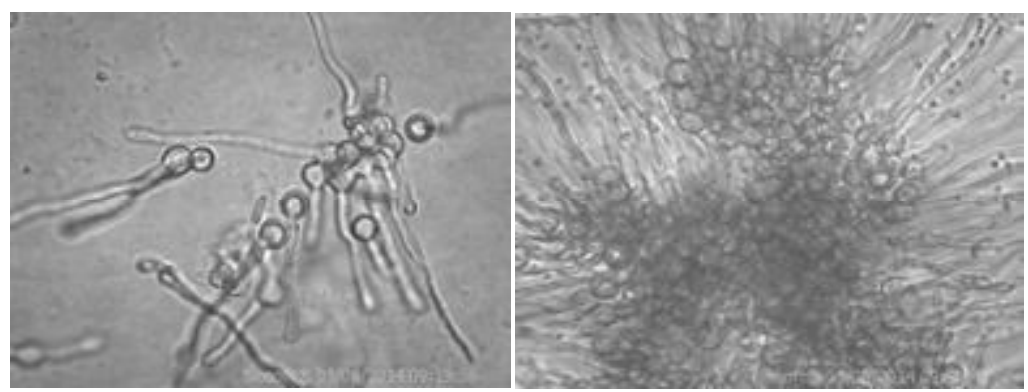

Gambar 2. Viabilitas (perkecambahan) jamur M. anisopliae setelah 24 jam masa inkubasi 
Hal ini berbeda dengan yang di nyatakan oleh Thalib et al. (2012), dalam penelitiannya bahwa, viabilitas konidia tertinggi pada umur simpan 1 bulan. Hal yang sama juga dinyatakan oleh Prayogo et al. (2005), bahwa waktu penyimpanan bioinsektisida yang efektif untuk membunuh larva $S$. incertulas adalah 1 bulan.

Bioaktivitas cendawan $M$. anisopliae. Bioaktivitas cendawan $M$. anisopliae terhadap larva instar $2 C$. pavonana pada formulasi pelet dan tepung dengan konsentrasi $10^{6}, 10^{7}$ dan $10^{8}$. Setelah data dianalisis menunjukkan mortalitas larva tidak berbeda nyata antar seluruh perlakuan (Tabel 2).

Dari Tabel 2 diketahui bahwa bioaktivitas cendawan entomopatogen setelah masa penyimpanan 10 minggu terhadap mortalitas larva, dengan menggunakan konsentrasi yang berbeda baik dalam formulasi pelet maupun formulasi tepung idak berbeda nyata antar seluruh perlakuan sampai pada pengamatan 7 hari setelah aplikasi. Namun mortalitas tertinggi terdapat pada formulasi pelet yaitu, pada konsentrasi $10^{7}$ dan $10^{8}$ konidia/ml, dengan mortalitas mencapai $100 \%$. Sedangkan mortalitas terendah terdapat pada konsentrasi $10^{6} \mathrm{konidia} / \mathrm{ml}$, akan tetapi untuk formulasi tepung pada konsentrasi $10^{6}, 10^{7}$ dan $10^{8}$ mortalitas larva hanya $86 \%$. Dari hasil tersebut untuk semua perlakuan dapat dikatakan efektif dalam mengendalikan hama $C$. pavonana, karena mortalitas larva yang dihasilkan ratarata diatas $85 \%$.

Hal ini sesuai dengan yang dinyatakan Prayogo et al. (2005), keefektifan cendawan entomopatogen dalam menginfeksi inang dapat dipengaruhi oleh kerapatan konidia, frekuensi aplikasi, umur inang, dan waktu penyimpanan cendawan entomopatogen. Selanjutnya Julistiyowatie (2011) juga menyebutkan bahwa umur biakan $M$. anisopliae sangat mempengaruhi virulensinya pada larva S. litura, biakan cendawan berumur 1 bulan paling efektif mengendalikan S. litura. Virulensi bioinsektisida yang disimpan lebih dari 2 bulan akan menurun, karena nutrisi dalam media banyak digunakan untuk memproduksi konidia sehingga cendawan kehabisan cadangan nutrisi. Pada bioinsektisida ini kerapatan konidia dan viabilitas konidia juga akan menurun.

Pengujian Formulasi di Lapangan. Pengujian formulasi di lapangan bertujuan untuk mengetahui lamanya cendawan $M$. anisopliae bertahan pada tanaman dan kemampuannya dalam mengendalikan hama $C$. pavonana. Setelah data dianalisis menunjukkan bahwa pengujian formulasi pelet dan formulasi tepung tidak berbeda nyata (Tabel 3).

Dari Tabel 3 diketahui bahwa mortalitas tertinggi terdapat pada formulasi pelet yaitu sebesar $90 \%$, sudah

Tabel 2. Bioaktivitas Jamur M. anisopliae Setelah Penyimpanan 10 Minggu terhadap Mortalitas Larva $C$. pavonana dengan Beberapa Konsentrasi

\begin{tabular}{ccccccccc}
\hline \multirow{2}{*}{ Formulasi } & Konsentrasi & \multicolumn{7}{c}{ Mortalitas larva hari ke... (\%) } \\
\cline { 2 - 8 } & Jumlah konidia/ml & 1 & 2 & 3 & 4 & 5 & 6 & 7 \\
\hline \multirow{3}{*}{ Pelet } & $10^{6}$ & 6,36 & 6,83 & 7,31 & 60,00 & 73,33 & 86,67 & 86,67 \\
& $10^{7}$ & 3,86 & 3,86 & 4,95 & 46,67 & 60,00 & 80,00 & 100,00 \\
& $10^{8}$ & 3,86 & 6,69 & 6,96 & 53,33 & 66,67 & 80,00 & 100,00 \\
\hline \multirow{3}{*}{ Tepung } & $10^{6}$ & 3,25 & 3,25 & 5,13 & 40,00 & 66,67 & 73,33 & 86,67 \\
& $10^{7}$ & 5,61 & 6,00 & 7,23 & 73,33 & 73,33 & 73,33 & 86,67 \\
& $10^{8}$ & 6,36 & 6,36 & 6,83 & 53,33 & 73,33 & 86,67 & 86,67 \\
\hline
\end{tabular}

Tabel 3. Lamanya Formulasi Cendawan M.anisopliae Bertahan di Lapangan terhadap Mortalitas Larva $C$. pavonana

\begin{tabular}{llllllll}
\hline \multirow{2}{*}{ Jenis Formulasi } & \multicolumn{6}{c}{ Lamanya formulasi bertahan di lapangan terhadap mortalitas larva hari ke... (\%) } \\
\cline { 2 - 8 } & 1 & 2 & 3 & 4 & 5 & 6 & 7 \\
\hline \multirow{2}{*}{ Pelet } & 35,00 & 70,00 & 90,00 & 90,00 & 90,00 & 90,00 & 90,00 \\
Tepung & 40,00 & 60,00 & 82,50 & 87,50 & 87,50 & 87,50 & 90,00 \\
\hline
\end{tabular}


terjadi pada hari ke-3 setelah aplikasi hingga akhir pengamatan 7 hari setelah aplikasi mortalitas larva tidak bertambah lagi, tetapi menunjukkan tidak berbeda nyata dengan perlakuan formulasi tepung. Hal ini disebabkan jumlah konidia yang efektif pada kedua jenis formulasi tersebut hanya bertahan 4 hari. Lamanya konidia bertahan pada tanaman dipengaruhi oleh lingkungan seperti cahaya dan kelembaban. Seperti yang dinyatakan oleh Tanada \& Kaya (1993) bahwa, konidia cendawan yang terkena langsung oleh sinar matahari dengan periode yang cukup lama, umumnya akan mati karena radiasi oleh sinar ultra violet. Selain itu Tanada (1959) dalam Hill (1975) juga berpendapat bahwa suhu dan kelembaban udara berpengaruh terhadap ketahanan hidup cendawan entomopatogen.

Semakin tinggi suhu maka kelembaban semakin rendah, dengan begitu konidia akan semakin cepat matinya. Selain itu lamanya penyimpanan juga berpengaruh terhadap lamanya konidia bertahan di tanaman.

\section{SIMPULAN}

Dari hasil penelitian yang telah dilakukan dapat disimpulkan bahwa formulasi dalam bentuk pelet maupun tepung menunjukkan hasil yang sama terhadap lamanya penyimpanan, kerapatan konidia, viabilitas, bioaktivitas serta lamanya cendawan $M$. anisopliae bertahan di lapangan.

\section{SANWACANA}

Penulis mengucapkan terima kasih kepada Dikti yang telah memberikan biaya penelitian Hibah Bersaing selama 2 tahun yaitu tahun I (2013) dan Tahun ke-2 (2014).

\section{DAFTAR PUSTAKA}

Alves SB, Rossi LS, Lopes RB, Tamai MA, \& Pereira RM. 2002. Beauveria bassiana yeastphase on agar medium and its pathogenicity againts Diatraea saccharalis (Lepidoptera: Cerambidae) and Tetranychus urticae (Acari: Tetranychidae). J. Invert. Pathol. 81: 70-77.

Bidochka MJ, Kamp AM, \& Decroos JNA. 2000. Insect pathogenic fungi: from genes to populations. Fungal Pathol. 42: 171-193.
Effendy TA. Uji toksisitas Bioinsektisida jamur Metarhizium sp. berbahan pembawa bentuk tepung untuk mengendalikan Nilaparvata lugens (Stal.) (Homoptera: Delphacidae). Prosiding Seminar Nasional Unsri, pp. 20-21 Oktober 2010.

Gabriel BP \& Riyanto. 1989. Metarhizium anisopliae (Metsch) Sor. Taksonomi, Patologi, Produksi, dan Aplikasinya. Proyek Pengembangan Tanaman Perkebunan, Departemen Pertanian, Jakarta.

Geden CJ \& Steinkraus DC. 2003. Evaluation of three formulations of Beauveria bassiana for control of lesser mealworm and hide beetle in Georgia poultry houses. J. Econ. Entomol. 96: 1602-1607.

Goettel MS. 1992. Fungal agents for biocontrol. In Lomer CJ \& Prior C (Eds.). Biological Control of Locust and Grasshoppers. Proceedings of workshop. International Institute of Tropical Agriculture pp. 122-132. Cotonou, Republic of Benin. CAB International. Wallingfort, Oxon.

Hasyim A, Nuraida, \& Trizelia. 2009. Patogenisitas jamur entomopatogen terhadap stadia telur dan larva hama kubis $C$. pavonana Fabricius. $J$. Hortikultura. 19(3): 334-343.

Hill D. 1975. Agricultural Insect Pest of the Tropics and Their Control. Department of Zoology, University of Hongkong. Cambridge University Press. Cambridge . London - New York Melbourne. Pp. 239-247.

Inglis GD, Goettel MS, Butt H, Strasser TM. 2001. Use of hyphomycetous fungi for managing insect pests. In: Butt TM, Jackson CW, \& Magan N. (Eds.). Fungi as Biocontrol Agents, Progress, Problems and Potential. pp. 23-69. London : CABI Publishing.

Junianto YD \& Sulistyowati E. 2000. Produksi dan aplikasi jamur B. bassiana (Deuteromycotina, Hypomycetes) untuk pengendalian penghisap buah kakao (Helopeltis spp.) dan penggerek buah kakao (Conopomorpha cramerella). Pelita Perkebunan 15: 1-19.

Kalshoven LGE. 1981. The Pests of Crops in Indonesia. Laan PA van der. penerjemah. Jakarta: IchtiarBaru-Van Hoeve. Revisi dari : De Plagen van de Cultuurgewassen in Indonesie. 
Luz C, Tigano MS, Silva IG, Cordeiro CMT \& Aljanabi SM. 1998. Selection of Beauveria bassiana and Metarhizium anisopliae isolates to control Triatoma infestans. Mem.Inst. Oswaldo Cruz 93: 839-846.

Milner RJ, Staples JA, \& Lutton GG. 1997. The effect of humidity on germination and infection of termites by the Hypomycetes, Metarhizium anisopliae. J. Invertebr. Pathol. 69(1): 64 - 69.

Myles TG. 2002. Isolation of Metarhizium anisopliae (Deuteromycotina: Hyphomecetes) from Reticulitermes flavipes (Isoptera: Rhinotermitidae) with convenient methods forits culture and collection of conidia. Sociobiology 40: 257-264.

Nuraida \& Hasyim A. 2009. Isolasi, identifikasi, dan karakterisasi jamur entomopatogen dari rhizosfir pertanaman kubis. J. Hortikultura 19(4): 419432.

Prayogo Y, Tengkano W, \& Marwoto. 2005. Prospek cendawan entomopatogen Metarhizium anisopliae untuk mengendalikan ulat grayak Spodoptera litura pada kedelai J. Litbang Pertanian. 24(1): 19-26.
Roddam LF \& Rath AD. 2000. Isolation and characterization of Metarhium anasopliae and Beauveria bassiana from subantarctic Macquarie Island. J. Invertebr. Pathol. 69: 285288.

Sastrosiswojo. 1996. Sistem Pengendalian Hama Terpadu dalam Menunjang Agribisnis Sayuran. Prosiding Seminar Ilmiah Nasional Komoditas Sayuran pp. 69-81. Balai Penelitian Tanaman Sayuran, Lembang 24 Oktober 1996.

Tanada Y \& Kaya H .1993. Insect Pathology. Academic Press Inc., San Diego, New York, Boston, London, Sydney, Tokyo, Toronto.

Thalib R, Salamah HE, Khodijah, Meidalima D, Thamrin T, Irsan C, \& Herlinda S. 2012. Lama Penyimpanandan Keefektifan Bioinsektisida dari Jamur Entomopatogen terhadap Larva Penggerek Kuning Batang Padi (Scirpophagai ncertulas). Prosiding InSINas pp. 281-286. 29-30 Nopember 2012. 